\title{
The Handprint Initiative, Empowering Teachers and Students towards Sdgs Actions
}

\author{
Wendy Quetzal Morel Schramm¹, Pablo Ruz Salmones² \\ Humboldt University/ Grupo Ya Quedó
}

\begin{abstract}
Today the future of our world is uncertain, and Education for Sustainable Development (ESD) plays the most significant role in shaping it. Nevertheless, the question arises whether ESD could and have achieved this result with the previous form of teaching. Student studies in several countries shows that learners have no positive attitudes towards the environment and social problems, exhibiting an increasing apathy, even an "helplessness" behaviour. Currently our learners lack of the motivation, self-efficacy, empower and competences to face the global challenges and become changemakers. In 2007 the Handprint concept was born as an aftereffect of questioning "Why we discussed only the negative carbon footprint?" and represent the belief that our actions make a difference. Therefore, the Handprint Initiative seeks to transform students' attitudes towards the environment and social challenges through its unique approach to the empowerment of all who take part in their formation. The Handprint Initiative is consisting in three stages: 1) Testing the instrument that gave the statistical basis to determine five crucial attitudes and the identification of learners with higher levels of ecoapathy; 2) Identify schools in Mexico City and Berlin to implement the Handprint Initiative. Design and implement and intervention for the schools. This consist of a survey for teachers and students, a teacher's workshop to integrate the Handprint concept and the relation with the SDGs, and the implementation inside the classroom. 3) Data recollection and analysis.
\end{abstract}

The repetitively implementation of the Handprint Initiative will allow the transformational impact in teaching.

Keywords: Attitudes; ecoapathy; empowerment; global challenges; self-efficacy 